\section{Antinuclear antibodies mitotic patterns and their clinical associations}

Damoiseaux et $\mathrm{al}^{1}$ recently reported an international consensus on antinuclear antibodies (ANA) based on 28 different patterns in order to harmonise the names and descriptions of the distinct HEp-2 indirect immunofluorescence assay (IIFA) patterns. The expert panel emphasised the clinical-serological relationships between immunofluorescence patterns and the corresponding test recommendations, rather than mechanistically testing antigen specificity (sometimes not commercially available), to provide the correct weight to the HEp2-IIFA pattern.

We appreciate the great effort made by these experts. However, we found that both in the original manuscript and the online supplementary material, limited mention was made of mitotic patterns and their possible clinical associations (with the exception of the NuMA-like pattern) which means that they are clinically relevant and which go against the primary objective of the consensus.

We recently analysed a nationwide cohort of 113491 sera consecutively tested for ANA which was positive in 60501 $(53 \%) .^{2}$ Of these, 592 samples with staining for anti-mitotic spindle apparatus (MSA) antigen patterns (NuMA/MSA-1, midbody/MSA-2, CENP-F/MSA-3 and centrosome) were chosen for further analysis. Of these, 116 patients had a conclusive diagnosis.

The most frequent pattern was NuMA $(65 / 116,56 \%)$ which had the highest ANA titres: mean 320 (range 80-2560) and was the only positive marker in $81.5 \%$ of patients, behaving as a monospecific antibody, a finding consistent with previous studies. ${ }^{3}$ In a novel description, this pattern was associated with chronic idiopathic urticaria (10/10 patients).

MSA-2 was the second most frequent pattern (30/116, 25\%) and had the lowest mean ANA titres (mean 80, range 80-640) and ENA positivity of all anti-MSA patterns $(3 / 30,10 \%)$. Thirteen of $30(43 \%)$ had connective tissue disease (CTD), mainly Sjögren syndrome (SS), rheumatoid arthritis and systemic lupus erythematosus. This pattern was also associated with sensorineural hearing loss (11/13). The centrosome pattern (17/116, 14.6\%) had the second highest frequency of extractable nuclear antigen (ENA) positivity, mostly ribonucleoprotein positive, and was associated with undifferentiated CTD. The autoantibodies to the centromere proteins-F (CENP-F) pattern was the least frequent $(4 / 116,3.4 \%)$, and only two patients had CTD (SS and vasculitis, respectively).

In a preliminary study of anti-MSA positive patients $(n=104)$, Virginia-Pascual et $a l^{4}$ found a prevalence of liver disease of up to $21 \%$ : $28.8 \%$ had hypertransaminasaemia ( $>2 \mathrm{SD}$ ) and $46.6 \%$ had cholestasis. The aetiology was heterogeneous, with toxic-metabolic pathology in $48 \%$, viral disease in $41 \%$ and autoimmune diseases in $10 \%$. Unfortunately, the study did not discriminate by patterns.
In the current consensus, for the mitotic and some cytoplasmic HEp2-IIFA patterns, the clinical association was based on antigen-specific immunoassays and not on the HEp-2 patterns as such. Pretest probability that corresponds to the prevalence of the disease and clinical suspicion is crucial for the relevance of any diagnostic test. The interpretation and importance of uncommon ANA patterns are a clinical challenge. A very low prevalence of these patterns make it difficult to establish close clinical associations between mitotic patterns and clinical syndromes. There remains much work still to be carried out in this expanding field.

\section{Juan F Betancur, ${ }^{1}$ José A Gómez-Puerta $~^{2}{ }^{2}$}

${ }^{1}$ Internal Medicine Department, IPS Sura Industriales, Medellín, Colombia ${ }^{2}$ Rheumatology Department, Hospital Clínic i Provincial, Barcelona, Spain

Correspondence to Dr José A Gómez-Puerta, Rheumatology Department, Hospital Clínic i Provincial, Barcelona 08036, Spain; jagomez@clinic.cat

Contributors Both authors contributed equally in the elaboration of the current manuscript including writing and editing process.

Funding The original work cited in the manuscript was funded by Dinámica IPS, Medellín, Colombia.

Competing interests None declared.

Patient consent for publication Not required.

Provenance and peer review Not commissioned; internally peer reviewed.

(c) Author(s) (or their employer(s)) 2020. No commercial re-use. See rights and permissions. Published by BMJ.

- Additional material is published online only. To view please visit the journal online (http://dx.doi.org/10.1136/annrheumdis-2019-215428).

\section{Check for updates}

To cite Betancur JF, Gómez-Puerta JA. Ann Rheum Dis 2020;79:e63.

Received 24 March 2019

Accepted 27 March 2019

Published Online First 29 April 2019

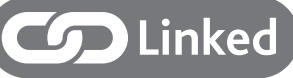

- http://dx.doi.org/10.1136/annrheumdis-2019-215439

Ann Rheum Dis 2020;79:e63. doi:10.1136/annrheumdis-2019-215428

ORCID ID

José A Gómez-Puerta http://orcid.org/0000-0001-8177-702X

\section{REFERENCES}

1 Dammoiseux J, Coelho-Andrade LE, Carballo OG, et al. Clinical relevance of HEp-2 indirect immunofluorescent patterns: the International consensus on ANA patterns (ICAP) perspective. Ann Rheum Dis 2019;0:1-11.

2 Betancur JF, Londoño A, Estrada VE, et al. Uncommon patterns of antinuclear antibodies recognizing mitotic spindle apparatus antigens and clinical associations. Medicine 2018;97:e11727.

3 Szalat R, Ghillani-Dalbin P, Jallouli M, et al. Anti-NuMA1 and anti-NuMA2 (anti-HsEg5) antibodies: clinical and Immunological features: a propos of 40 new cases and review of the literature. Autoimmunity Reviews 2010;9:652-6.

4 Pascual V, Perez I, Sánchez-Ramón S, et al. Antibodies to mitotic apparatus: new association with cholestatic liver disease. American Journal of Gastroenterology 2015;110:1736-7 